\title{
Cerebrospinal fluid pressure and the eye
}

\author{
William H Morgan, ${ }^{1}$ Chandrakumar Balaratnasingam, ${ }^{1}$ Christopher R P Lind, ${ }^{2}$ \\ Steve Colley, ${ }^{3}$ Min H Kang, ${ }^{1}$ Philip H House, ${ }^{1}$ Dao-Yi Yu ${ }^{1}$
}

${ }^{1}$ Lions Eye Institute, University of Western Australia, Nedlands, Western Australia, Australia

${ }^{2}$ School of Surgery, University of Western Australia, West Australian Neurosurgical Service, Sir Charles Gairdner Hospital, Hospital Avenue, Nedlands, Western Australia, Australia

${ }^{3}$ Royal Perth Hospital, Perth, Western Australia, Australia

\section{Correspondence to} Professor William H Morgan Lions Eye Institute, University of Western Australia, Nedlands, WA 6009, Australia; billmorgan@lei.org.au

Received 27 January 2015 Revised 4 March 2015 Accepted 22 March 2015 Published Online First 15 April 2015

\section{CrossMark}

To cite: Morgan WH, Balaratnasingam $\mathrm{C}$, Lind CRP, et al. $\mathrm{Br} J$ Ophthalmol 2016;100: 71-77.

\section{ABSTRACT}

Cerebrospinal fluid pressure (CSFP) interacts with intraocular pressure (IOP) and blood pressure to exert a major influence upon the eye, particularly the optic nerve head region. There is increased interest regarding the influence of CSFP upon disorders affecting this region, in particular glaucoma and idiopathic intracranial hypertension. Additionally, a high proportion of astronauts develop features similar to idiopathic intracranial hypertension that persist for years after returning to Earth. The factors that affect the CSFP influence upon the optic nerve and globe are likely to influence the outcome of various ophthalmic disorders.

\section{INTRODUCTION}

The optic nerve head separates the central nervous system and cerebrospinal fluid pressure (CSFP) from the intraocular structures and intraocular pressure (IOP). The lamina cribrosa and its constituent neural, vascular and connective tissue elements are very sensitive to alterations in pressure across this region, with follow-up effects into the rest of the eye. Such changes influence the occurrence of glaucoma, idiopathic intracranial hypertension and venous occlusions.

\section{ANATOMY}

The optic nerve subarachnoid space (ONSAS) surrounds the optic nerve as it leaves the cranial cavity up to the posterior globe where it is terminated anteriorly by the sclera. ${ }^{1}$ Along its path there are numerous trabeculae and septae whose shape varies with some thickening towards the termination of the subarachnoid space (figure 1). ${ }^{2}$ Internal to the ONSAS lies the pia mater and then the optic nerve proper. Externally lies the dura mater and intraconal orbital tissue. On closer examination using tracer and specialised immunohistochemical stains, lymphatic structures containing CSF material can be identified in the tissue surrounding the termination of the ONSAS. ${ }^{3-5}$ These lymphatic structures appear more prominent in lower mammals, such as rodents. ${ }^{67}$

\section{PRESSURES AND DIFFERENCES}

IOP averages $15 \mathrm{~mm} \mathrm{Hg}$ with a normal range of $10-21 \mathrm{~mm} \mathrm{Hg}$ in most populations ${ }^{8}$ and is generated by the balance between production from the ciliary body and egress through the trabecular meshwork and uvea. There is a small increase with age from $15.8 \mathrm{~mm} \mathrm{Hg}$ at age 50 years to $16.1 \mathrm{~mm} \mathrm{Hg}$ at age 80 years, although this effect is linked to the rise in systemic blood pressure. ${ }^{9}$

CSF is formed in the choroid plexus and flows through the ventricular system into the subarachnoid space where some is thought to flow down the
ONSAS traversing the trabeculae and septae present in it. ${ }^{10}$ The bulk of CSF is thought to drain out through the arachnoid granulations, however, up to $30 \%$ of CSF drains out via lymphatics in the olfactory bulb and ONSAS in lower mammals ${ }^{11}$ with an unknown proportion flowing out through these systems in primates and humans (figure 1). The CSFP, like IOP, is pulsatile having a small phase difference with peak IOP lagging behind peak CSFP but their trough pressures coincide. ${ }^{12}$ Unlike IOP, the CSFP is markedly altered by postural changes, with the normal range of CSFP in the lateral decubitus position being 5 to $15 \mathrm{~mm} \mathrm{Hg}$ but in the sitting position being -10 to $0 \mathrm{~mm} \mathrm{Hg}$ at eye level. ${ }^{13}$ Although IOP doesn't change as much as CSFP with postural change it does increase by 2-4 mm Hg when lying down from sitting. ${ }^{14}$ Hence, one should take into account the posture when interpreting results of CSFP measurements. CSFP tends to reduce with age in adulthood, from mean $11.5 \mathrm{~mm} \mathrm{Hg}$ in less than 50 year-olds to $9.0 \mathrm{~mm} \mathrm{Hg}$ in 70 year-olds. ${ }^{15}$

Production and drainage of CSF and aqueous are influenced by hydroxysteroid dehydrogenase with increased CSFP effect in obesity. ${ }^{16}$ Stimulation of certain regions of the rat brain increases IOP, CSFP and blood pressure to varying degrees and varying latency. ${ }^{17}$ It is likely that other humeral and neural stimuli influence CSFP and IOP.

\section{MEASUREMENT OF CSFP}

Currently, invasive techniques involving lumbar puncture or cranial burr holes are required for CSFP measurement. The development of non-invasive techniques for CSFP measurement would be a major advance for diagnosis and monitoring of various disorders. Previous attempts using transcranial Doppler, tympanic membrane reflectivity and optic nerve sheath diameter by ultrasound or MRI have given largely inaccurate measurements. ${ }^{18} 19$ The two most promising avenues being currently explored are refinement of ophthalmodynamometric measures of venous pulsation pressure (figure 2) and balancing intracranial/orbital ophthalmic artery flow velocities. ${ }^{20-22}$ Some groups have begun using multivariate algorithms incorporating blood pressure and body mass index as indirect indicators of CSFP, however one should remain aware of the limitations and dependencies of this technique. ${ }^{23} 24$

\section{RELATIONSHIP BETWEEN ONSAS PRESSURE AND INTRACRANIAL PRESSURE}

It has been assumed that ONSAS pressure is equivalent to intracranial pressure and is likely to be the case in healthy animals. ${ }^{25}$ However, the work of Killer and coauthors clearly demonstrates the 


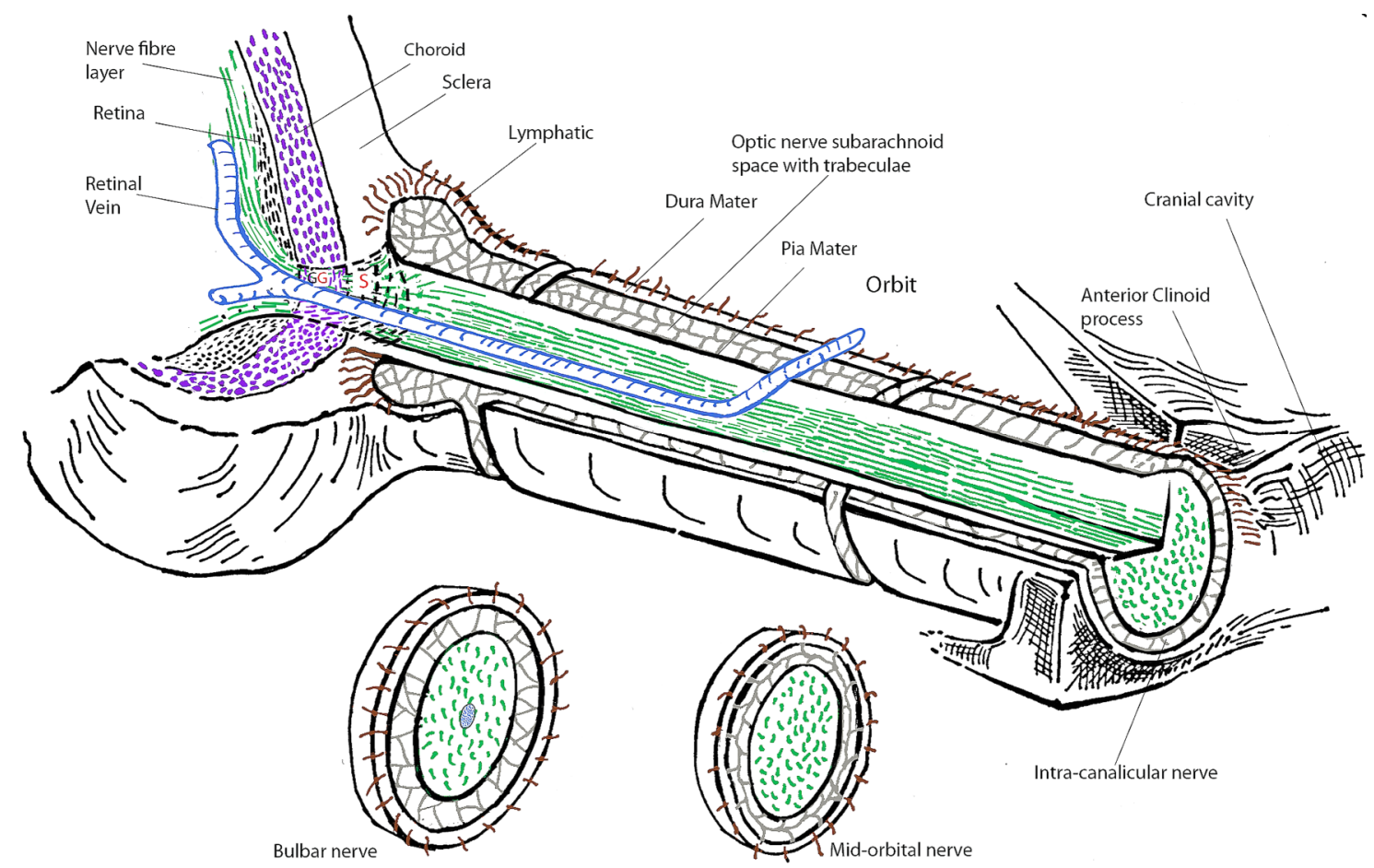

Figure 1 Key anatomical features of the optic nerve and eye in relation to the optic nerve subarachnoid space demonstrating the path to the intracranial cavity. The variation in trabeculae is shown and adapted from Killer et al [2]. Glial lamina cribrosa (G) and scleral (collagenous) lamina cribrosa (S) are shown. Central retinal artery is omitted for clarity.

presence of significantly large trabeculae, resembling fenestrated sheets along the ONSAS pathway (figure 1$)^{26}$ and that in some conditions, such as normal tension glaucoma and others, there is relative stasis of CSF flow along this pathway. ${ }^{27}$ They may alter

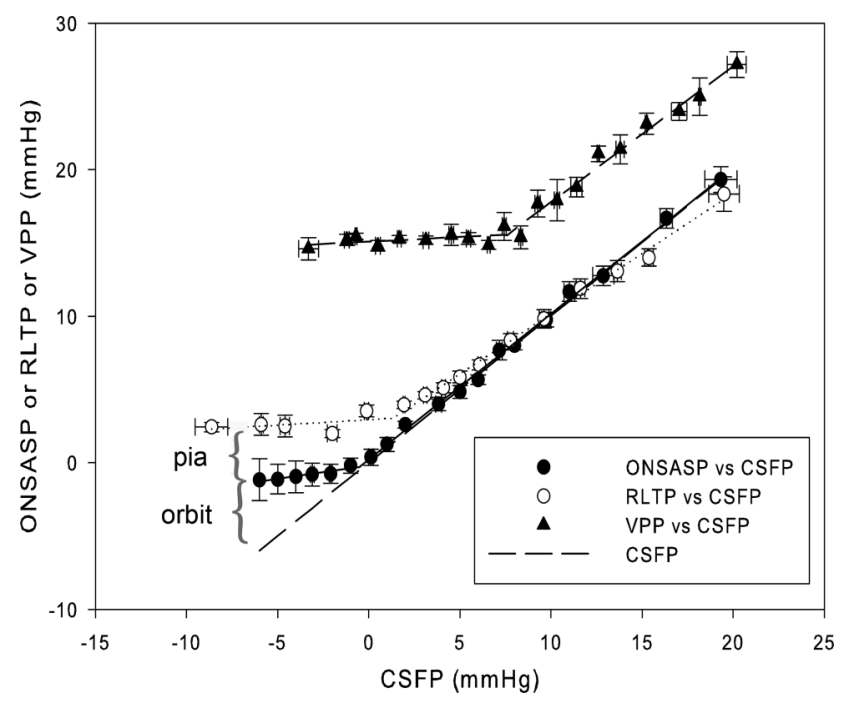

Figure 2 The relationship of key pressures $( \pm$ SEM) to intracranial cerebrospinal fluid pressure (CSFP) in the dog. A strong linear relationship is seen between optic nerve subarachnoid space pressure (ONSASP O), retrolaminar tissue pressure (RLTP $O$ ), venous pulsation pressure (VPP) by ophthalmodynamometry $(\boldsymbol{\Lambda})$ and intracranial cerebrospinal fluid pressure (CSFP - - ) above certain levels. Below these CSFP levels the pressures are constant. VPP is the minimum intraocular pressure (IOP) required to induce retinal vein pulsation. Lines of best fit are included. The difference between ONSAS and RLTP occurs across the pia mater (pia) and the difference between intracranial CSFP and ONSAS pressure is probably due to orbital pressure (orbit). fluid flow along the ONSAS although the flexibility of the septae may not impede pressure transmittance. However, significant trabecular changes such as following meningitis or other diseases may effectively block CSF flow and cause a disruption of pressure transmittance. In the normal situation we tend to assume that the ONSAS pressure is equivalent to intracranial pressure, however, another factor must be considered and this is the orbital tissue pressure found to be $2.6-4.4 \mathrm{~mm} \mathrm{Hg}$ in the supine position using needles inserted into the orbit. ${ }^{28} 29$ Tissue pressure measurement using needle insertion tends to give a slightly higher value than when less invasive micropipette techniques are used, ${ }^{30}$ so true orbital tissue pressure may be lower than these values. When a person is sitting or standing and the intracranial pressure falls to zero or below at eye level, this is likely to be transmitted along the ONSAS. If orbital tissue pressure is greater than the intracranial pressure then it will tend to compress and, hence, collapse the ONSAS and force CSF fluid back into the intracranial compartment. It may also compress regions of the ONSAS causing loculation with lack of pressure transmission. This presumed influence of orbital tissue pressure is supported by experimental data (figure 2) in the dog where below CSFP $0 \mathrm{~mm} \mathrm{Hg}$ the ONSAS pressure remains at $0 \mathrm{~mm} \mathrm{Hg}$.

\section{THE OPTIC NERVE RETROLAMINAR TISSUE PRESSURE}

The retrolaminar tissue pressure (RLTP) is the interstitial pressure within the optic nerve neural tissue just posterior to the lamina cribrosa. It is not always equivalent to ONSAS pressure with a variable pressure difference occurring across the pia mater indicating some pial elastic effect upon the RLTP ${ }^{25}$ When there is a low external pressure the elasticity of the pia mater tends to elevate RLTP and this has been demonstrated experimentally whereby at ONSAS pressures of $0 \mathrm{~mm} \mathrm{Hg}$ in the dog, the retrolaminar pressure is $3 \mathrm{~mm} \mathrm{Hg}$ and remains at this level until the ONSAS and intracranial pressures rise to $3 \mathrm{~mm} \mathrm{Hg}$ or above (figure 2). ${ }^{25}$ Above this pressure, the tension exerted by 
the pia mater reduces and the RLTP tends to equilibrate directly with the ONSAS. When the intracranial pressure is low there are likely to be two mechanisms that buffer the RLTP: the orbital tissue pressure tending to compress the ONSAS and the elasticity of the pia mater.

\section{PRESSURE DIFFERENCE AND PRESSURE GRADIENT ACROSS THE LAMINA CRIBROSA}

Tissue pressure measurements across the optic nerve into the retrolaminar region demonstrate a pressure gradient across the lamina cribrosa (figure 3). ${ }^{25}{ }^{31}$ In the dog, having an IOP of $15 \mathrm{~mm} \mathrm{Hg}$ and RLTP of $3 \mathrm{~mm} \mathrm{Hg}$ at CSFP $0 \mathrm{~mm} \mathrm{Hg}$ with a lamina thickness of $531 \mu \mathrm{m}$, the average translaminar pressure gradient (TLPG) is $23 \mathrm{~mm} \mathrm{Hg} / \mathrm{mm}$ tissue and this doubles to 47 $\mathrm{mm} \mathrm{Hg} / \mathrm{mm}$ tissue and this doubles to $47 \mathrm{~mm} \mathrm{Hg} / \mathrm{mm}$ tissue as the IOP rises to $28 \mathrm{~mm} \mathrm{Hg} .{ }^{25}$ In the human, the posterior (collagenous) lamina thickness measures mean $341 \mu \mathrm{m}$ compared with $539 \mu \mathrm{m}$ for the combined glial and collagenous lamina. The normal human TLPG is estimated at being between 20 $\mathrm{mm} \mathrm{Hg} / \mathrm{mm}$ and $33 \mathrm{~mm} \mathrm{Hg} / \mathrm{mm}$ tissue, with the true value likely being closer to $33 \mathrm{~mm} \mathrm{Hg} / \mathrm{mm}$ given indirect evidence that the gradient exists across the collagenous lamina. ${ }^{32} 33$

Forces which act upon tissues are caused directly by pressure gradients and so the magnitude of force and its effect upon a tissue can be minimised by reducing the gradient. ${ }^{34}$ Practically speaking this means that a thicker lamina cribrosa can spread out the gradient over a greater distance and hence reduce the shear stress acting across this tissue. The corollary is that a thinner lamina cribrosa amplifies the pressure gradient. Patients with established glaucoma have lamina thinning and tend to progress at a greater rate for a given $\mathrm{IOP}^{35}$

\section{PHYSIOLOGICAL FUNCTIONS ALTERED BY PRESSURE GRADIENTS}

In primate models of raised IOP and CSFP, orthograde axonal transport and retrograde axonal transport are inhibited at the level of the lamina cribrosa with accumulation of intracellular material including mitochondria and other vesicles. Axonal transport accumulation occurs mainly at the posterior lamina region in animal glaucoma models, ${ }^{36}$ and is inhibited in rabbit vagus nerve when the pressure difference exceeds $30 \mathrm{~mm} \mathrm{Hg}$ and the gradient exceeds $45 \mathrm{~mm} \mathrm{Hg} / \mathrm{mm} .{ }^{37}$ It has not been shown experimentally whether the pressure difference or gradient has greatest effect upon axonal transport.

When the IOP is raised leading to an elevated translaminar pressure gradient, significant neurofilament changes occur within several hours followed by changes in the microtubules which are structures vital for axonal transport conductance. ${ }^{38} 39$ These cytoskeletal changes are likely to be fundamental to the cause of the axonal transport changes. Cytochrome oxidase activity also increases in the collagenous lamina region with increased TLPG indicating increased metabolic requirements in this region. ${ }^{40}$

The central retinal vein traverses the lamina cribrosa and is subject to the translaminar pressure gradient particularly because the venous transmural pressure is close to zero, ${ }^{41}{ }^{42}$ meaning that the surrounding tissue pressure generally affects the pressure within the vessel lumen. It is likely that the pressure gradient falls along the central retinal vein as it traverses the lamina cribrosa. Assuming such, a gradient of $33 \mathrm{~mm} \mathrm{Hg} / \mathrm{mm}$ is much higher than the typical $0.7 \mathrm{~mm} \mathrm{Hg} / \mathrm{mm}$ found in venules. ${ }^{43}$ Venous endothelial cells within the posterior (collagenous) laminar region are closer, morphologically speaking, to arterial endothelial cells than to other venous endothelial cells (figure 4), demonstrating that they are subject to higher sheer stresses as a result of the pressure gradient. ${ }^{33}{ }^{44}$ It is possible that these sheer stresses and morphological changes are exacerbated when the pressure gradient is increased in glaucoma.

\section{INTERACTIONS WITHIN THIS REGION}

IOP and CSFP are pulsatile, being influenced by the cardiac cycle with CSFP having an additional influence from the respiratory cycle (figure 3). IOP and CSFP pulsatility affect optic nerve tissue pressure pulsatility (figure 3 ). ${ }^{31}$ One important clinical observation is the phenomenon of spontaneous venous pulsation close to the central retinal vein exit into the optic nerve, found in $95 \%$ of normal subjects. We have found that venous pulsation phase is in time with the IOP and CSFP phase. ${ }^{12}$ Classical theories had taught that pulsation would be counter phase to IOP and that the systolic peak of IOP that would lead to venous compression, ${ }^{45}{ }^{46}$ however recent work suggests that CSFP pulse drives venous pulse timing and so has a more dominant effect upon key venous haemodynamic properties. ${ }^{12}$ The reasons for spontaneous venous pulsation are complicated and probably relate largely to the eye resembling a Starling resistor. ${ }^{47}$ Monkey and dog experiments demonstrate that an average $8 \mathrm{~mm} \mathrm{Hg}$ pressure difference between IOP and CSFP is required for the induction of venous pulsation. ${ }^{48-50}$

\section{ABNORMAL ANATOMY}

\section{Enlargement of the ONSAS}

The ONSAS width is increased in many patients with raised CSFP. This is a significant relationship and has been used to estimate intracranial pressure non-invasively with several algorithms being published..$^{5152}$ However, enlargement of the ONSAS may be due to other factors such as loculation of CSF within the ONSAS. These may be part of the explanation for the observation that ONSAS width is increased in some patients with normal tension glaucoma.

\section{Myopia}

Persons with high myopia tend to have a thin lamina cribrosa $(207 \mu \mathrm{m})$ compared with a normal $458 \mu \mathrm{m}$. Lamina thickness decreases in patients with moderately advanced glaucoma $(201 \mu \mathrm{m})$ and patients with myopic glaucoma $(78 \mu \mathrm{m}) .^{53}$ Such reductions in laminar thickness will double or quadruple the gradient effect of the pressure difference. This is likely to influence progression rates of glaucoma and may explain why patients with severe glaucoma and myopia tend to progress even at lower IOP levels. ${ }^{35} 5455$ Persons with myopia also have an increased width of the ONSAS termination and a thin posterior sclera. Recent optical coherence tomography (OCT) scanning using swept source demonstrates that the posterior staphylomata frequently seen in persons with high myopia tend to overlie the region of the enlarged ONSAS termination (figure 5). ${ }^{56}$ The presumed reason for the staphyloma is the pressure difference across the thinned sclera between the IOP compartment and the ONSAS compartment leading to posterior distortion of the sclera just as posterior distortion of the lamina cribrosa occurs in glaucoma. The smaller degrees of optic disc excavation seen in persons with myopia with glaucoma may in part be due to the fact that the gradient is occurring across and causing distortion of the sclera and lamina cribrosa.

\section{Possible septal changes in ONSAS}

In patients with idiopathic intracranial hypertension and normal tension glaucoma it has been observed that there is a lower flow of CSF from the intracranial compartment along the ONSAS and this may be due to thickened trabeculae leading to increased 
Figure 3 Micropipette tissue pressure measurements in $\operatorname{dog}(B)$ as the micropipette is passed from the vitreous region, the prelaminar region, the lamina and into the retrolaminar optic nerve. Oscillations from the respiratory and cardiac cycles can be seen. Intraocular pressure (A), cerebrospinal fluid pressure (C) and blood pressure (D). Lamina cribrosa was from $558 \mu \mathrm{m}$ to $919 \mu \mathrm{m}$.
Depth of penetration ( $\mu \mathrm{m})$

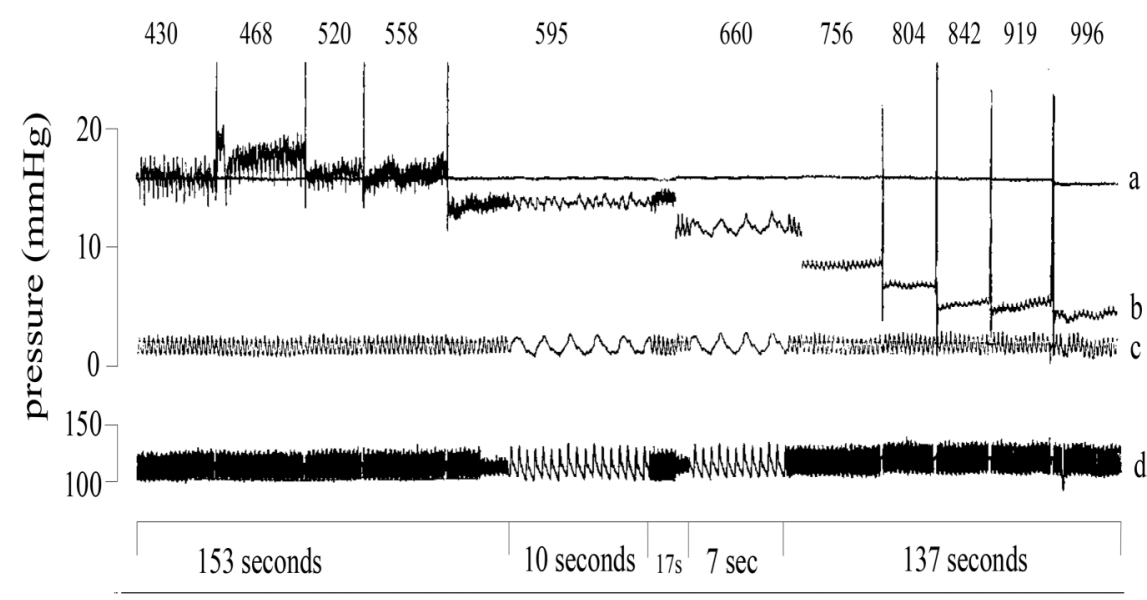

Time flow resistance along the ONSAS. ${ }^{27} 57$ This reduced flow may have metabolic consequences by leading to stagnation and reduced removal of toxic metabolites as well as reduced delivery of necessary metabolites to regions, particularly near the termination of the ONSAS. It also may impact upon functioning of the lymphatic and neural tissues within this region.

\section{Raised translaminar pressure gradient}

The TLPG is most simply described by the difference between IOP and RLTP divided by the distance between the two pressure compartments. Physiologically speaking this means the difference between IOP and ONSAS pressure, allowing for the buffering effects of orbital pressure and the pia mater and divided by the lamina cribrosa thickness. One must also take into account changes in posture if one is using CSFP measurements from the lumbar spine. The caveats concerning general assumptions that the pressures are equivalent between the intracranial compartment, lumbar spine and ONSAS must be considered and weighed carefully at each set of observations. So, an increased TLPG can theoretically be caused by increased IOP and reduced CSFP and also by reduced buffering, that is, a lower orbital tissue pressure and reduced elasticity of the pia
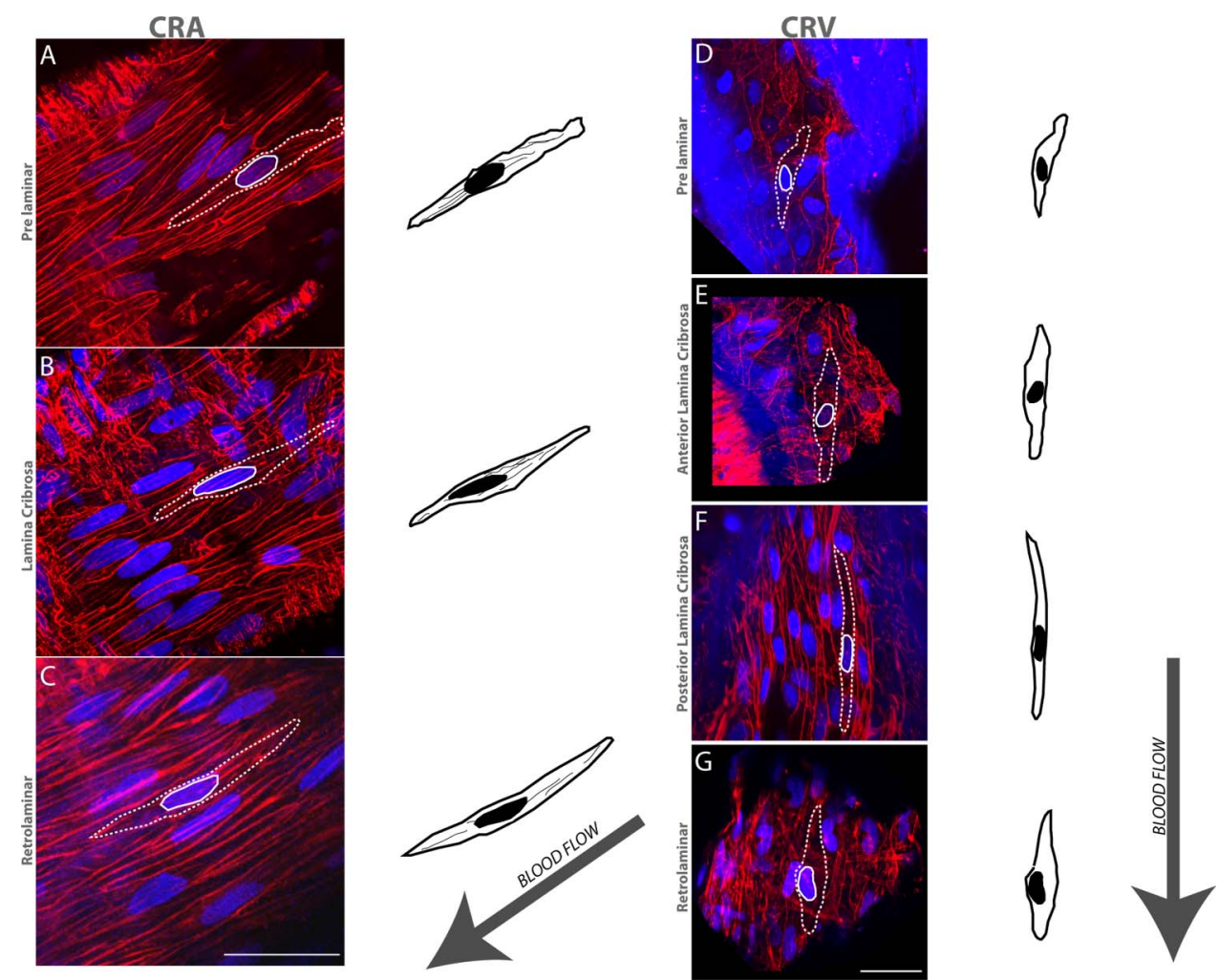

Figure 4 Central retinal arterial (CRA) (A-C) and central retinal venous (CRV) (D-G) endothelial morphology. Confocal microscope images and schematic outlines demonstrate endothelial morphology in the prelaminar, anterior lamina cribrosa, posterior lamina cribrosa and retrolaminar regions. In the posterior lamina cribrosa region, venous endothelial cells $(F)$ appeared similar to the arterial endothelium displaying spindle-shaped morphology. Scale bar, $50 \mu \mathrm{m}$. 

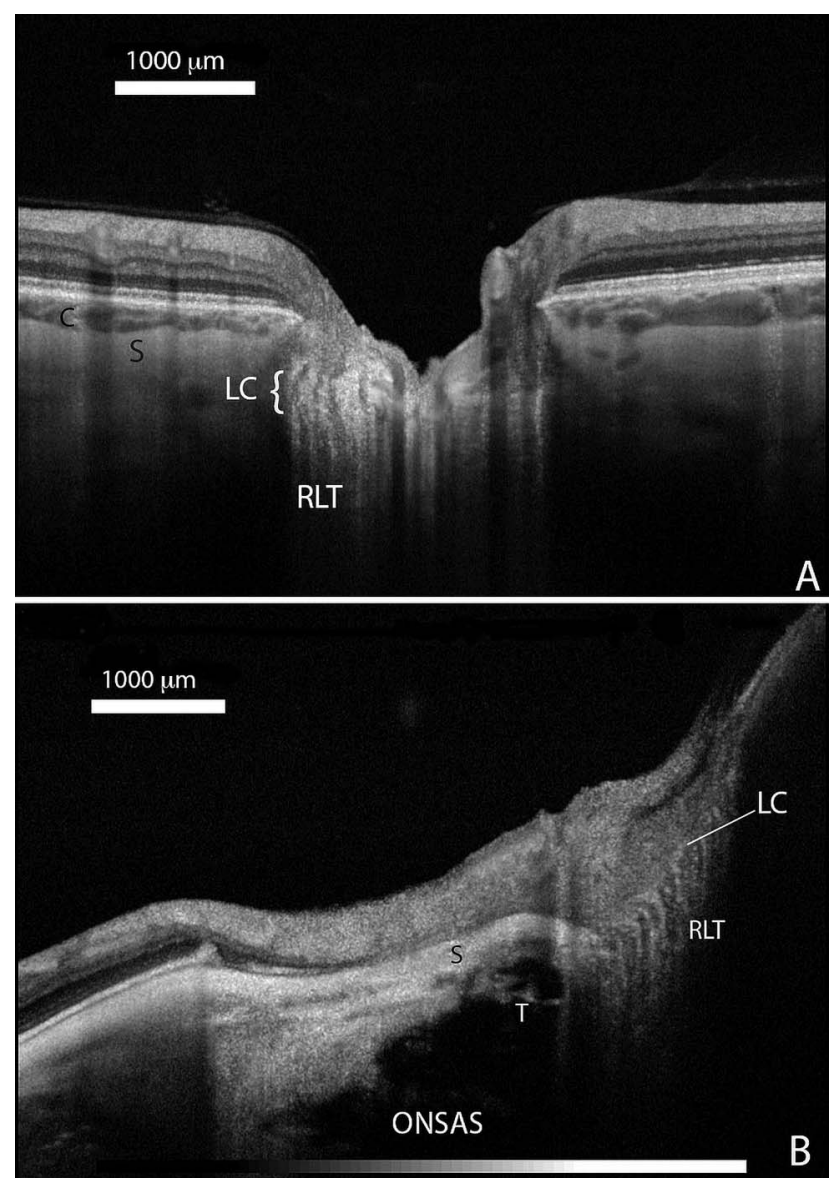

Figure 5 Swept source OCT of eye with mild glaucoma (A) having a collagenous lamina cribrosa (LC) thickness approximating $300 \mu \mathrm{m}$. Some retrolaminar tissue (RLT) is shown. The choroid (C) and sclera (S) are well developed. In the highly myopic eye the sclera $(S)$ is thin, particularly under the posterior staphyloma region, which overlies the large optic nerve subarachnoid space (ONSAS). One trabecula (T) is clearly seen. The collagenous LC is very thin and the RLT is clearly seen. Scale bars shown.

mater leading to greater transmittance of low pressures from the orbit and ONSAS directly to the retrolaminar optic nerve. The classic example of raised TLPG is that of standard glaucoma when IOP is elevated. ${ }^{8}$ However, much recent work has shown that compared with normal subjects, CSFP is reduced in primary open angle glaucoma especially in normal tension glaucoma. ${ }^{58}$ Additionally, recent work using a chronic low CSFP monkey model demonstrates glaucoma-like changes to the nerve fibre layer with disk rim haemorrhage. ${ }^{60}$

As one ages the IOP tends to rise gradually and CSFP tends to drop slightly. Orbital tissues tend to atrophy with age leading to a sunken orbital appearance in many subjects and pia mater changes may occur leading to reduced pressure buffering properties around the optic nerve, all of which would tend to lower the RLTP and exacerbate the TLPG. It is of some concern that prostaglandin analogues appear to hasten orbital fat atrophy. ${ }^{61}$ It should be clearly stated and understood that the pressures within the orbit and the changes of orbital pressure and pia mater are poorly understood at present.

\section{Reduced or reversed translaminar pressure gradient}

Idiopathic intracranial hypertension and other disorders that lead to a rise in CSFP are well known causes of papilloedema comprising anterior optic nerve swelling with an anterior shift of the lamina cribrosa along with retinal vein engorgement and tortuosity. Most of these features can be understood by considering the effect of raised CSFP and subsequent raised RLTP leading to a reversed pressure gradient with inhibition of orthograde axonal transport and stasis predominantly within prelaminar and anterior (glial) laminar regions but also in the posterior (scleral) laminar and retrolaminar regions. ${ }^{62} 63$ The neural swelling is associated with compression of the central retinal and other veins, which is compounded by the direct effect of the raised CSFP causing elevated intraocular venous pressure. ${ }^{64}$ This is thought to account for the venous engorgement, and probably results in some reduced anterior optic nerve perfusion leading to further damage to the ganglion cell axons. Idiopathic intracranial hypertension can be an aggressive disease ${ }^{65}$ but tends to respond well to treatments leading to a reduction in overall intracranial pressure or local ONSAS pressure through either optic nerve sheath fenestration or ventricular peritoneal shunting procedures. ${ }^{66}$ The relative place of these therapies is still somewhat controversial although optic nerve sheath fenestration may be effective in patients with less trabecular obstruction to the ONSAS fluid flow pathway but may not reduce intracranial pressure and headache. ${ }^{66}$ This may account for the observation that a single optic nerve sheath fenestration helps preserve vision in both eyes of just some subjects.

Multivariate models for estimating CSFP suggest that CSFP elevation may be a risk factor for diabetic retinopathy development. $^{23}$

\section{Prolonged space flight}

Prolonged space flight by astronauts in space for more than 6 months frequently $(20 \%)$ leads to a clinical syndrome bearing marked similarities to idiopathic intracranial hypertension with papilloedema, also some cotton wool spots as well as choroidal folds and a hyperopic refractive shift. ${ }^{67}$ MRI scans show elevated optic disks with an anteriorly shifted macula and dilated ONSAS. ${ }^{68}$ These subjects have increased intracranial pressure, which persists for months and years after their return to earth. The explanation for this phenomenon is likely to involve the fact that in microgravity there is a cephalad fluid shift with increased venous pressures and impaired lymphatic flow around the head. ${ }^{69} 70$ Both factors may conspire to impede CSF outflow and lead to an increased average CSFP, which is not reduced or ameliorated by postural changes, that is, by standing. It is difficult to explain why the elevated CSFP persists for so long upon returning to earth but the most likely explanation involves a permanent change in the outflow system, either involving the arachnoidal granulations or the lymphatic outflow apparatus around the olfactory bulb, optic nerve and other regions. It is possible that in space with CSF stagnation along the ONSAS, toxic changes are occurring within the anterior optic nerve involving lymphatics leading to some permanent change in CSF outflow in this region.

\section{CONCLUSION}

We hope to have demonstrated that the influence of CSFP upon the eye and in particular the anterior optic nerve is significant and relevant to common ocular diseases. There is a rapidly growing body of literature reporting significant effects of CSFP upon glaucoma as well as diseases causing papilloedema and other disorders like diabetes. A simplistic understanding incorporating only CSFP and IOP without considering lamina cribrosa properties, orbital tissue, pia mater and subarachnoid space properties is unlikely to give a complete understanding of these 
common disorders. Some of our understanding is hindered by the lack of an accurate non-invasive measurement method for CSFP.

Correction notice This article has been corrected since it was published Online First. The provenance and peer review statement has been corrected.

Contributors WHM: has contributed to the conception, design and writing of the review manuscript. He has also contributed to the acquisition, analysis and interpretation of the data. CB: has contributed to the acquisition of the data. CRPL: has contributed to the acquisition of the data. SC: has contributed to the writing of the manuscript. MHK: has contributed to the acquisition of the data. PHH: has contributed to the acquisition of the data. D-YY: has contributed to the acquisition of the data.

Funding Supported by an NHMRC project grant 1020367.

Competing interests None.

Provenance and peer review Commissioned; externally peer reviewed.

\section{REFERENCES}

1 Jonas JB, Berenshtein E, Holbach L. Anatomic relationship between lamina cribrosa, intraocular space, and cerebrospinal fluid space. Invest Ophthalmol Vis Sci 2003;44:5189-95.

2 Killer $H E$, Laeng HR, Flammer J, et al. Architecture of arachnoid trabeculae, pillars, and septa in the subarachnoid space of the human optic nerve: anatomy and clinical considerations. Br J Ophthalmol 2003;87:777-81.

3 Killer HE, Jaggi GP, Miller NR, et al. Does immunohistochemistry allow easy detection of lymphatics in the optic nerve sheath? J Histochem Cytochem 2008;56:1087-92.

4 Ludeman W, von Rautenfeld DB, Samii M, et al. Ultrastructure of the cerebrospinal fluid outflow along the optic nerve into the lymphatic system. Childs Nerv Syst 2005;21:96-103.

5 Erlich SS, McComb JG, Hyman S, et al. Ultrastructure of the orbital pathway for cerebrospinal fluid drainage in rabbits. J Neurosurg 1989;70:926-31.

6 McComb JG, Hyman S, Johanson RB, et al. Lymphatic drainage of cerebrospinal fluid in the primate. Pathophysiology of the blood brain barrier. New York: Elsevier Science Publishers, 1990:421-38.

7 McComb JG, Davson H, Hyman S, et al. Cerebrospinal fluid drainage as influenced by ventricular pressure in the rabbit. J Neurosurg 1982;56:790-7.

8 Hollows FC, Graham PA. Intra-ocular pressure, glaucoma, and glaucoma suspects in a defined population. Br J Ophthalmol 1966;50:570-86.

9 Rochtchina E, Mitchell P, Wang JJ. Relationship between age and intraocular pressure: the Blue Mountains Eye Study. Clin Experiment Ophthalmol 2002;30:173-5.

10 Davson H, Welch K, Segal MB. The physiology and pathophysiology of the cerebrospinal fluid. Edinburgh: Churchill Livingstone, 1987.

11 Bradbury MW, Cole DF. The role of the lymphatic system in drainage of cerebrospinal fluid and aqueous humour. J Physiol 1980;299:353-65.

12 Morgan WH, Lind CR, Kain $S$, et al. Retinal vein pulsation is in phase with intracranial pressure and not intraocular pressure. Invest Ophthalmol Vis SCi 2012;53:4676-81.

13 Magnaes B. Body position and cerebrospinal fluid pressure. Part 2. Clinical studies on orthostatic pressure and the hydrostatic indifferent point. J Neurosurg 1976;44:698-705.

14 Jain MR, Marmion VJ. Rapid pneumatic and Mackey-Marg applanation tonometry to evaluate the postural effect on intraocular pressure. $\mathrm{Br} J$ Ophthalmol 1976;60:687-93.

15 Fleischman D, Berdahl JP, Zaydlarova J, et al. Cerebrospinal fluid pressure decreases with older age. PLOS ONE 2012;7:e52664.

16 Sinclair AJ, Walker EA, Burdon MA, et al. Cerebrospinal fluid corticosteroid levels and cortisol metabolism in patients with idiopathic intracranial hypertension: a link between 11 beta-HSD1 and intracranial pressure regulation? J Clin Endocrinol Metab 2010;95:5348-56.

17 Samuels BC, Hammes NM, Johnson PL, et al. Dorsomedial/Perifornical hypothalamic stimulation increases intraocular pressure, intracranial pressure, and the translaminar pressure gradient. Invest Ophthalmol Vis Sci 2012;53:7328-35.

18 Raboel PH, Bartek J Jr, Andresen M, et al. Intracranial pressure monitoring: invasive versus non-invasive methods-a review. Crit Care Res Practice 2012;2012:950393.

19 Geeraerts T, Newcombe VFJ, Coles JP, et al. Use of T2-weighted magnetic resonance imaging of the optic nerve sheath to detect raised intracranial pressure. Crit Care 2008:12:R114-14.

20 Siaudvytyte L, Januleviciene I, Ragauskas A, et al. Update in intracranial pressure evaluation methods and translaminar pressure gradient role in glaucoma. Acta ophthalmologica 2015;93:9-15.

21 Ragauskas A, Daubaris G, Dziugys A, et al. Innovative non-invasive method for absolute intracranial pressure measurement without calibration. Acta Neurochir Supp/ 2005;95:357-61.
22 Querfurth HW, Arms SW, Lichy CM, et al. Prediction of intracranial pressure from noninvasive transocular venous and arterial hemodynamic measurements: a pilot study. NeurocritCare 2004;1:183-94.

23 Jonas JB, Wang N, Xu J, et al. Diabetic retinopathy and estimated cerebrospinal fluid pressure. The Beijing Eye Study 2011. PLOS ONE 2014;9:e96273..

24 Jonas JB, Nangia V, Wang N, et al. Trans-lamina cribrosa pressure difference and open-angle glaucoma. The central India eye and medical study. PLOS ONE 2013;8: e82284.

25 Morgan WH, Yu DY, Alder VA, et al. The Correlation between Cerebrospinal Fluid Pressure and Retrolaminar Tissue Pressure. Inv Ophthalmol Vis Sci 1998:39:1419-28.

26 Killer HE, Laeng HR, Flammer J, et al. Architecture of arachnoid trabeculae, pillars, and septa in the subarachnoid space of the human optic nerve: anatomy and clinical considerations. Br J Ophthalmol 2003;87:777-81.

27 Killer HE, Miller NR, Flammer J, et al. Cerebrospinal fluid exchange in the optic nerve in normal-tension glaucoma. Br J Ophthalmol 2012;96:544-8.

28 Moller PM. The pressure in the orbit. Acta Ophthalmol Supp/ 1955;43:1-100

29 Riemann CD, Foster JA, Kosmorsky GS. Direct orbital manometry in patients with thyroid-associated orbitopathy. Ophthalmology 1999;106:1296-302.

30 Wiig $\mathrm{H}$, Reed RK, Aukland K. Measurement of interstitial fluid pressure: comparison of methods. Ann Biomed Eng 1986;14:139-51.

31 Morgan WH. Pressure gradients across the optic disk [PhD]. University of Western Australia, 1999.

32 Balaratnasingam C, Morgan WH, Johnstone V, et al. Histomorphometric measurements in human and dog optic nerve and an estimation of optic nerve pressure gradients in human. Exp Eye Res 2009;89:618-28.

33 Kang MH, Balaratnasingam C, Yu PK, et al. Morphometric characteristics of central retinal artery and vein endothelium in the normal human optic nerve head. Invest Ophthalmol Vis Sci 2011;52:1359-67.

34 Srivastava A, Sood A, Joy PS, et al. Principles of physics in surgery: the laws of mechanics and vectors physics for surgeons-part 2. Indian J Surg 2010;72:355-61.

35 Leske MC, Heijl A, Hyman L, et al. Predictors of long-term progression in the early manifest glaucoma trial. Ophthalmology 2007;114:1965-72.

36 Quigley H, Anderson DR. The dynamics and location of axonal transport blockade by acute intraocular pressure elevation in primate optic nerve. Invest Ophthalmol 1976;15:606-16.

37 Hahnenberger RW. Inhibition of fast anterograde axoplasmic transport by a pressure barrier. The effect of pressure gradient and maximal pressure. Acta Physiol Scand 1980;109:117-21.

38 Balaratnasingam C, Morgan WH, Bass L, et al. Axonal transport and cytoskeletal changes in the laminar regions after elevated intraocular pressure. Invest Ophthalmol Vis Sci 2007;48:3632-44.

39 Yu DY, Cringle SJ, Balaratnasingam C, et al. Retinal ganglion cells: Energetics, compartmentation, axonal transport, cytoskeletons and vulnerability. Prog Retin Eye Res 2013;36:217-46.

40 Balaratnasingam C, Pham D, Morgan WH, et al. Mitochondrial cytochrome C oxidase expression in the central nervous system is elevated at sites of pressure gradient elevation but not absolute pressure increase. J Neurosci Res 2009;87:2973-82.

41 Morgan WH, Yu DY, Cooper RL, et al. Retinal artery and vein pressures in the dog and their relationship to aortic, intraocular, and cerebrospinal fluid pressure. Microvasc Res 1997;53:211-21.

42 Westlake WH, Morgan WH, Yu DY. A pilot study of in vivo venous pressures in the pig retinal circulation. Clin Experiment Ophthalmol 2001;29:167-70.

43 Zweifach BW. Quantitative studies of microcirculatory structure and function. I. Analysis of pressure distribution in the terminal vascular bed in cat mesentery. Circ Res 1974;34:843-57.

44 Kang MH, Balaratnasingam C, Yu PK, et al. Alterations to vascular endothelium in the optic nerve head in patients with vascular comorbidities. Exp Eye Res 2013;111:50-60.

45 Levine DN. Spontaneous pulsation of the retinal veins. Microvasc Res 1998;56:154-65

46 Baurmann M. Uber die entstehung und klinische bedentung des netzhautvenenpulses. Dtsch Ophthalmol Ges 1925;45:53-9.

47 Meyer-Schwickerath $\mathrm{R}$, Kleinwachter T, Firsching $\mathrm{R}$, et al. Central retinal venous outflow pressure. Graefes Arch Clin Exp Ophthalmol 1995;233:783-8.

48 Morgan WH, Yu DY, Balaratnasingam C. The role of cerebrospinal fluid pressure in glaucoma pathophysiology: the dark side of the optic disc. J Glaucoma 2008;17:408-13.

49 Rios-Montenegro EN, Anderson DR, Noble JD. Intracranial pressure and ocular haemodynamics. Arch Ophthalmol 1973;89:52-8.

50 Gibbs FA. Relationship between the pressure in the veins on the nerve head and the cerebrospinal fluid pressure. Arch Neurol Psychiatry 1936;35:292-5.

51 Xie $X$, Zhang $X$, Fu J, et al. Noninvasive intracranial pressure estimation by orbital subarachnoid space measurement: the Beijing Intracranial and Intraocular Pressure (iCOP) study. Crit Care 2013;17:R162.

52 Kimberly HH, Shah S, Marill K, et al. Correlation of optic nerve sheath diameter with direct measurement of intracranial pressure. Acad Emerg Med 2008;15:201-4. 
53 Jonas JB, Berenshtein E, Holbach L. Lamina cribrosa thickness and spatial relationships between intraocular space and cerebrospinal fluid space in highly myopic eyes. Invest Ophthalmol Vis Sci 2004;45:2660-5.

54 Forsman E, Kivela T, Vesti E. Lifetime visual disability in open-angle glaucoma and ocular hypertension. I Glaucoma 2007;16:313-19.

55 Perdicchi A, lester M, Scuderi G, et al. Visual field damage and progression in glaucomatous myopic eyes. Eur J Ophthalmol 2007;17:534-7.

56 Ohno-Matsui K, Akiba M, Moriyama M, et al. Imaging retrobulbar subarachnoid space around optic nerve by swept-source optical coherence tomography in eyes with pathologic myopia. Invest Ophthalmol Vis Sci 2011;52:9644-50.

57 Killer HE, Jaggi GP, Flammer J, et al. The optic nerve: a new window into cerebrospinal fluid composition? Brain 2006;129:1027-30.

58 Berdahl JP, Allingham R, Johnson DH. Cerebrospinal fluid pressure is decreased in primary open-angle glaucoma. Ophthalmology 2008;115:763-8.

59 Ren RJ, Jonas JB, Tian GG, et al. Cerebrospinal fluid pressure in glaucoma A prospective study. Ophthalmology 2010;117:259-66.

60 Yang D, Fu J, Hou R, et al. Optic neuropathy induced by experimentally reduced cerebrospinal fluid pressure in monkeys. Invest Ophthalmol Vis Sci 2014;55:3067-73.

61 Jayaprakasam A, Ghazi-Nouri S. Periorbital fat atrophy —an unfamiliar side effect of prostaglandin analogues. Orbit 2010;29:357-9.
62 Tso MO, Hayreh SS. Optic disc edema in raised intracranial pressure. III. A pathologic study of experimental papilledema. Arch Ophthalmol 1977;95:1448-57.

63 Tso MO, Hayreh SS. Optic disc edema in raised intracranial pressure. IV. Axoplasmic transport in experimental papilledema. Arch Ophthalmol 1977:95:1458-62.

64 Hayreh MS, Hayreh SS. Optic disc edema in raised intracranial pressure. I. Evolution and resolution. Arch Ophthalmol 1977:95:1237-44.

65 Sorensen PS, Krogsaa B, Gjerris F. Clinical course and prognosis of pseudotumor cerebri. A prospective study of 24 patients. Acta Neurol Scand 1988:77:164-72.

66 Kapoor KG. More than meets the eye? Redefining idiopathic intracranial hypertension. Int I Neurosci 2010;120:471-82.

67 Mader TH, Gibson CR, Pass AF, et al. Optic disc edema, globe flattening, choroidal folds, and hyperopic shifts observed in astronauts after long-duration space flight. Ophthalmology 2011;118:2058-69.

68 Kramer LA, Sargsyan AE, Hasan KM, et al. Orbital and intracranial effects of microgravity: findings at 3-T MR imaging. Radiology 2012;263:819-27.

69 Bradbury MW, Westrop RJ. Factors influencing exit of substances from cerebrospinal fluid into deep cervical lymph of the rabbit. J Physiol 1983;339:519-34.

70 Berdahl JP, Yu DY, Morgan WH. The translaminar pressure gradient in sustained zero gravity, idiopathic intracranial hypertension, and glaucoma. Med Hypotheses 2012;79:719-24 